\title{
Entre a recuperação patrimonial e a questão da moradia: projetos de renovação urbana para o centro de Santos
}

\author{
Between the recovery of historical heritage and the housing issue: urban \\ renewal projects to downtown Santos
}

Maria Carolina Maziviero

Universidade São Judas Tadeu (USJT), São Paulo, SP, Brasil

\section{Resumo}

O objeto de estudo deste artigo é a cidade de Santos, mais especificamente a gestão pública municipal, no que se refere aos projetos para a região central da cidade e às suas implicações sociais. Devido à vertiginosa valorização do solo urbano em Santos nos últimos 15 anos, combinada com uma gestão pública marcada pelo patrimonialismo e pelo crescente atendimento aos interesses do grande capital privado, houve dois processos bastante nítidos na cidade: a) a expulsão de parcela da população de Santos, principalmente para outras cidades da Baixada Santista; b) a mercantilização do patrimônio arquitetônico e urbanístico, que tem sido preservado, desde que não interfira nos interesses do mercado imobiliário. 0 trabalho apresenta como objetivo principal a descrição, a análise e a avaliação das políticas públicas urbanas para o centro de Santos, no que tange ao seu conjunto de valores, lógica de funcionamento, interesses atendidos e suas implicações sociais.

Palavras-chave: Revitalização de centros urbanos. Gestão empresarial de cidades. Habitação popular.

\section{Abstract}

The study case is the city of Santos, specifically the municipal public administration, concerning urban policies. Due to the large increase in Santos land value in the last fifteen years, and to the public management marked by both patrimonialism as the growing attention to the interests of large private capital, which is organized through associations and representations of class, there were two very clear processes in the city: a) the expulsion of part of Santos population, including the lower middle class, mainly to other cities of the region; and b) the commodification of urban and architectural heritage which has been preserved, since it did not interfere with the real estate market interests. The work has as main objective the description, analysis and evaluation of Santos urban policies, regarding their set of values, its operating logic, and the attendance of interests inside and outside the city.

Keywords: Urban renewal of downtown areas. Urban management. Social housing.

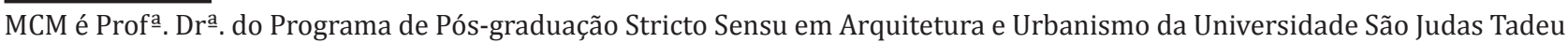
(USJT), e-mail: mcarolmazi@hotmail.com 


\section{A retomada do desenvolvimento do centro de Santos}

A região central de Santos, no final do século XIX, foi local de moradia de comerciantes de vários portes, incluindo uma elite de comissários e de corretores, além de banqueiros e financiadores-importadores que transacionavam o café. Com o adensamento populacional provocado pela inauguração da estrada de ferro da São Paulo Railway e pela reestruturação do porto em um núcleo rodeado por uma área alagadiça, inúmeras doenças se alastravam. Assim, a reforma e a ampliação do porto mostravam-se essenciais para a consolidação da economia cafeeira do Estado de São Paulo, mesmo porque as epidemias que assolavam a cidade passaram a atingir a capital e o interior da província, levadas, principalmente, pelos imigrantes que desembarcavam em Santos rumo às fazendas de café (Bernardini, 2006; Maziviero, 2008; Nunes, 2001).

Com as Reformas Urbanas, a cidade se expandiu em direção à praia e teve como principal eixo estruturador dessa expansão a Avenida Conselheiro Nébias. Após a consolidação da elite na orla, os antigos bairros centrais e o trecho inicial da avenida passaram a ser ocupados por trabalhadores braçais, como os imigrantes e os ex-escravos, além de pequenos comerciantes. Os antigos casarões foram pouco a pouco transformados em cortiços ou tendo alguns dos seus cômodos alugados a estranhos. 0 mesmo aconteceu com a Vila Nova, ocupada por segmentos sociais de baixa renda e que, ao longo do tempo, consolidou seu caráter de bairro comercial e de pequenas indústrias, deixando de ser exclusivamente residencial.

0 que vemos se consolidar são dois vetores distintos do crescimento urbano no período: de um lado, o vetor da exclusão, que compreendeu as zonas norte e noroeste de Santos e um pouco da central; do outro, o vetor da participação e da valorização imobiliária, que seguia ao longo da Avenida Conselheiro Nébias em direção às praias, onde surgiam os primeiros casarões e palacetes da elite, além dos hotéis e dos clubes de luxo que transformavam a orla em um núcleo de lazer da nova cidade "modernizada". Esse vetor abarcava a zona sul santista.

Portanto, a expansão de Santos, após as Reformas Urbanas, foi marcada pela cisão da cidade em dois núcleos sociais, pois, à medida que empurraram a população pobre para a periferia, também criaram condições de ocupação e de valorização da orla, assim como de parte da zona intermediária entre cais e praias. Essas transformações se enquadram no conceito de privatismo porque, embora comandadas pelo Estado, foram reivindicadas pelo capital privado oriundo do apogeu da economia cafeeira com o objetivo de garantir sua reprodução.

Já no século XXI, a área central passa a ser novamente foco da política urbana santista por meio de programas que defendem a revitalização dessa região como ponto fundamental para o desenvolvimento econômico e social da cidade como um todo, tal qual recomendado por Jordi Borja. Para esse autor, patrono do modelo catalão de planejamento estratégico de cidades, o espaço que diferencia uma cidade das outras, capaz de torná-la diferenciada e competitiva na atração de capitais, é o centro, ao qual aspectos simbólicos e culturais podem ser associados por estratégias de marketing - um dos elementos fundamentais para a efetivação desse modelo de planejamento por produzir verdadeiros espetáculos urbanos por meio da utilização da cultura como principal insumo.

O modelo amplamente divulgado pela experiência de Barcelona é a transposição, para entidades públicas e depois para as cidades, do método de administração e planejamento de empresas. Essa "adaptação" começou nos Estados Unidos e, posteriormente, foi levada à Europa, chegando ao Brasil pelo Rio de Janeiro nos anos de 1990, como demonstra Novais (2010). A tônica desse modelo de planejamento de cidades assenta-se, portanto, sobre um Estado empreendedor; suas ações vinculadas à lógica do mercado podem acarretar processos de exclusão e segregação social no espaço urbano.

O contexto brasileiro constituía-se em um campo preparado para a acolhida da ideia do planejamento estratégico. Os arranjos sociopolíticos brasileiros, descritos por Faoro (1958) como patrimonialismo estatal, colocavam interesses privados de alguns grupos acima de toda a sociedade e atuavam diretamente sobre a atividade econômica. Faoro aponta que a instrumentalização do Estado patrimonial pelo estamento burocrático se utiliza de sua posição privilegiada para impor à coletividade seus objetivos particularistas. Para o autor, essas condições de governabilidade se constituíram em obstáculos à formação de um projeto de nação que levasse em conta os interesses coletivos, sempre rechaçados. Campante (2003) acrescenta que o liberalismo se constitui em um poderoso instrumento e em uma boa justificativa 


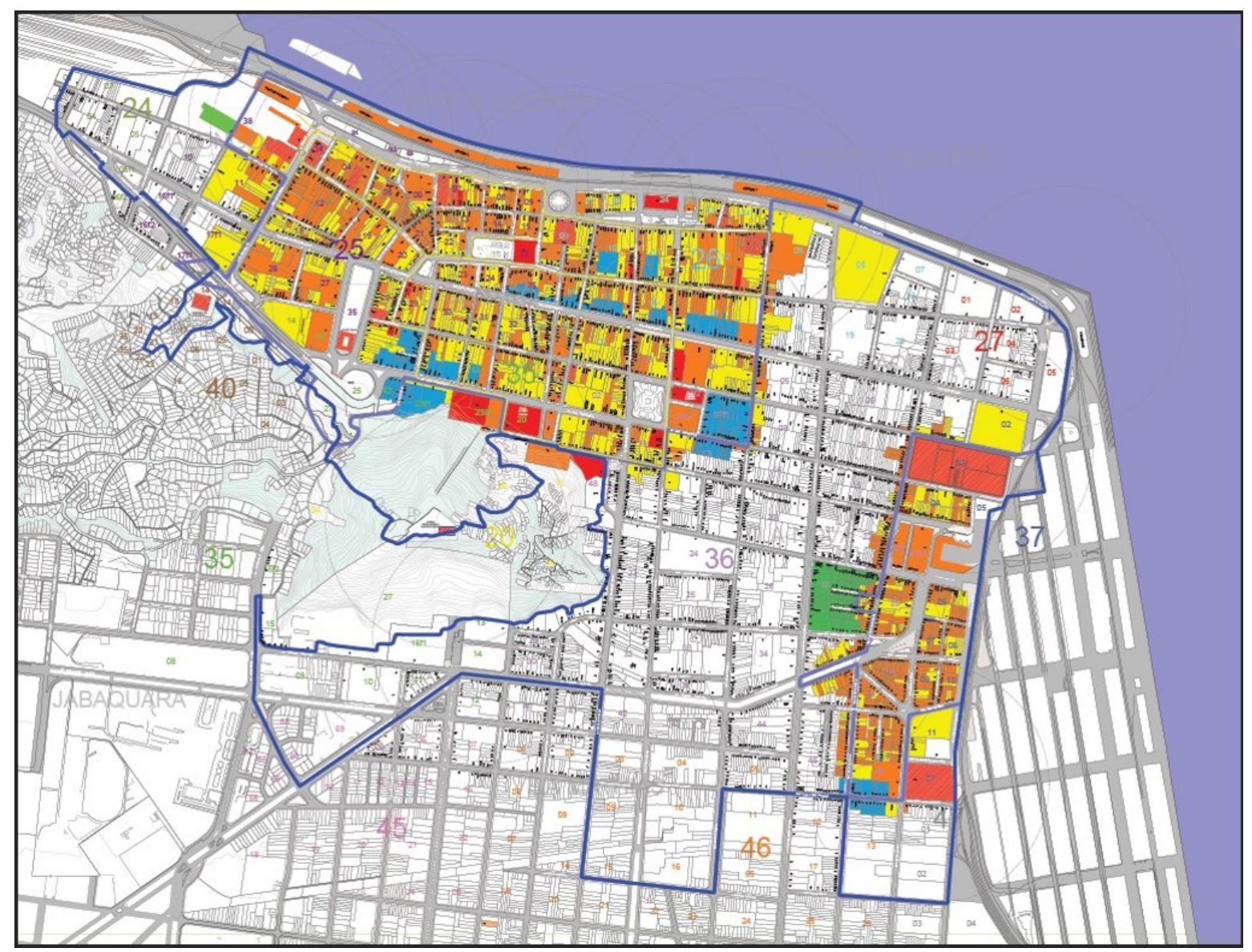

Figura 1 - Área de atuação do Programa Alegra Centro Fonte: SEPLAN (2015).

para o domínio privado de grupos econômicos sobre o coletivo, principalmente no Brasil, onde as pressões das camadas populares ainda são fracas. Nos anos de 1990, quando a primazia do mercado e a defesa dos interesses particularistas foram mais acentuadas pela conjuntura político-ideológica internacional, a efetivação da cidadania no país e a inclusão de grupos fragilizados se tornaram ainda mais difíceis.

Em Santos, embora a retomada do desenvolvimento do centro tenha sido anunciada no Plano Diretor de 1968 (Santos, 1968d), somente a partir do plano de 1998, claramente influenciado pelas mudanças ocorridas mundialmente na economia e no planejamento urbano, que algumas áreas foram definidas como passíveis de revitalização urbana ${ }^{1}$. Esse plano se tornou um marco no modelo de desenvolvimento adotado pela cidade, pois a lógica privatista, que percorreu a política urbana

\footnotetext{
${ }^{1}$ Os chamados Corredores de Proteção Cultural (CPC) foram, posteriormente, ampliados para Área de Proteção Cultural (APC).
}

de Santos ao longo de um século, encontrou nele solo fértil para se desenvolver por completo.

\section{Programa de Revitalização e} Desenvolvimento da Região Central Histórica de Santos: Alegra Centro

As ações de revitalização, requalificação e recuperação nas Áreas de Proteção Cultural (APCs) são dirigidas pelo Programa de Revitalização e Desenvolvimento da Região Central Histórica de Santos, o Alegra Centro, transformado em Lei Complementar no 470 por meio da sanção do prefeito da cidade em 2003 (Santos, 2003). 0 programa visa à retomada do desenvolvimento socioeconômico do centro, utilizando como estratégia o resgate do patrimônio cultural, por intermédio do fomento à preservação do patrimônio histórico, e a requalificação urbana com solução habitacional somente na região da Vila Nova (Figura 1). 
Segundo a prefeitura, o programa Alegra Centro já recebeu investimentos de R \$ 194 milhões, dos quais $40 \%$ são de recursos municipais, $29 \%$, da iniciativa privada, $21 \%$, estadual e federal, e $10 \%$, público-privado (Prefeitura Municipal de Santos, 2013). Os empreendedores são orientados quanto à recuperação, uso e ocupação dos edifícios, e o município oferece o serviço de um Escritório Técnico de Revitalização para fornecer apoio aos investidores. São concedidos incentivos fiscais com isenção de tributos como Imposto Predial e Territorial Urbano (IPTU), Imposto sobre Serviços de Qualquer Natureza (ISS) e Imposto sobre Transmissão "Inter Vivos" de Bens Imóveis e de Direitos Reais sobre Imóveis (ITBI), além da venda do potencial construtivo.

Desde 2003, foram concedidas 382 isenções fiscais. Segundo a prefeitura, a lei já contribuiu para 490 obras de conservação, restauração e reforma. Somam-se, ao todo, 1.805 imóveis com níveis de proteção 1 (NP1 - preservação total) e 2 (NP2 proteção parcial: fachadas, inclusive coberturas). No entorno, são mais 769 imóveis com nível 3 de proteção (NP3), ou seja, menos restritivo onde há a possibilidade de novos projetos desde que mantida a tipologia predominante dos imóveis NP1 e NP2. Os níveis de proteção dos imóveis são definidos pelo respectivo órgão no processo de tombamento devido à sua representatividade, seu estado de conservação e sua localização - em consonância com o Plano Diretor de Desenvolvimento e Expansão Urbana.

Além de um forte apelo ao investidor privado, são realizadas campanhas de marketing pela municipalidade, com eventos que têm a cultura como âncora de atração do público consumidor. Como apontado por Santos (2014), a Prefeitura, com apoio de parceiros do setor privado, promoveu uma série de eventos culturais para tentar alavancar as potencialidades da região central e atrair frequentadores também para o período noturno ${ }^{2}$. Todas essas tentativas mostram o alinhamento da gestão pública municipal ao modelo de

\footnotetext{
${ }^{2}$ Alguns exemplos foram: Caminhada Histórica pelo Centro de Santos; o Carnabonde; a Maratona Cultural Caros Amigos de Santos; o Projeto Música na XV, a Virada Cultural Santista, instituição da marca turística oficial inspirada no bonde e no Centro Histórico; o Espaço Cultural Casa de Frontaria Azulejada; a restauração do Teatro Coliseu e do Teatro Guarany; a ampliação da linha turística do bonde - que passou de 1,7 para $5 \mathrm{~km}$ de extensão percorrendo 32 pontos de interesse cultural -, entre outros.
}

planejamento estratégico, o qual atrelava as políticas culturais às urbanas para alavancar o preço do solo em áreas centrais degradadas (Arantes, 2000).

As isenções fiscais são garantidas desde que o imóvel restaurado e preservado desenvolva atividades comerciais e de serviços, mas o uso habitacional não é contemplado. No primeiro semestre de 2008, cinco anos após a implementação do Alegra Centro, foram apresentadas as linhas básicas de um segundo programa, o Alegra Centro Habitação. Seu objetivo era melhorar as condições de habitabilidade dos imóveis já ocupados nas áreas limítrofes ao perímetro do Alegra Centro, além de atrair novos empreendimentos residenciais. Entretanto, o programa habitacional não tem conseguido atender à demanda por moradia devido, especialmente, à grande valorização do solo urbano estimulada pelas diretrizes do Alegra Centro. Somam-se a isso o caráter elitizado dos projetos público/privados previstos para a área central ${ }^{3}$, bem como o alto padrão dos serviços já instalados por incentivo da municipalidade ${ }^{4}$.

${ }^{3}$ Alguns dos projetos já divulgados pela Prefeitura são: Museu
Pelé (inaugurado em junho/2014); Terminal de Cruzeiros
da Marina Porto Santos - parte do Complexo Náutico que
contará com apart-hotéis, escritórios e estacionamentos;
sede da Unidade de Negócio de Exploração e Produção
da Bacia de Santos (UN-BS), construída em um terreno de
25 mil m² ${ }^{2}$ que pertencia à prefeitura da cidade e que custou
R\$15,18 milhões. Em 2011, o então gerente-geral da Unidade
de Operações de Exploração e Produção da Bacia de Santos,
José Luiz Marcusso, divulgou que o complexo seria composto
por três torres. Nelas estariam concentrados os empregados
da estatal de toda a bacia - Cabo Frio (RJ) a Florianópolis
(SC) - e seria a central de controle operacional da Bacia de
Santos de forma definitiva, mas até hoje a central funciona
no Rio de Janeiro. Em meio às denúncias envolvendo a
Petrobrás e à desaceleração econômica, a estatal freou os
investimentos no centro de Santos, atingindo a cadeia de
projetos imobiliários e outros negócios na região. Apenas
uma das três torres foi entregue em novembro de 2014 e
não há informações sobre as outras duas do projeto.

${ }^{4} 0$ projeto Porto Valongo Santos já teve processo licitatório, mas encontra-se paralisado. Tem como objetivo a remodelação dos armazéns portuários da região central, “[...] transformando-os em um dos maiores polos turísticos, de lazer e entretenimento empresarial do Brasil. Esse empreendimento será uma das principais intervenções urbanas em áreas portuárias já realizadas no Brasil” (Caldatto, 2008 apud Souza, 2012, p. 133). Baseia-se em projetos de revitalização de famosas marinas internacionais e conta, para isso, com auxílio da empresa vencedora da licitação Ove Arup \& Partners, 
A área central, então decadente pelo abandono do Poder Público desde a saída das classes abastadas nas primeiras décadas do século XX e, por isso, habitada por uma população de baixa renda, vê-se em um processo de valorização do solo urbano pelo upgrading cultural ${ }^{5}$. A atração de usuários solventes se torna diretamente proporcional à expulsão dos insolventes, processo mais conhecido como gentrification ${ }^{6}$. Percebe-se que a expulsão da população pobre, que antes era consequência da política urbana, agora se torna a própria política em si, necessária para retomada da economia local. Nesse discurso do setor privado legitimado pela municipalidade, o poder político migra para as mãos de grandes investidores, e a construção democrática da cidade é ameaçada.

\section{A questão da moradia popular em Santos}

Desde a segunda metade do século XIX, Santos já passava por conflitos para localização habitacional de sua população economicamente mais fragilizada, inicialmente em escala intraurbana, como visto, e depois extrapolando os limites do município. As soluções encontradas pelo Poder Público para

responsável pelos projetos de revitalização em Hong Kong, Austrália e Coreia do Sul. Esse projeto demandará outros investimentos, inclusive com financiamento público, para viabilizar a infraestrutura necessária à sua implantação, como a construção de uma passagem subterrânea para o tráfego de caminhões, o chamado "mergulhão", que está a cargo do governo federal, por meio da Companhia Docas do Estado de São Paulo (CODESP). Na ocasião da apresentação do projeto, foram reservados R 300 milhões do Programa de Aceleração do Crescimento (PAC) para as obras do "mergulhão". O Porto Valongo previa uma base oceanográfica da Universidade de São Paulo (USP), além de um novo terminal de cruzeiros marítimos, restaurantes, lojas, escritórios, marina pública e um museu do porto. Contudo, desde 2012 a prefeitura não divulgou mais nenhuma informação sobre o início do projeto ou se ainda faz parte da agenda municipal.

${ }^{5}$ Utilizando a expressão cunhada por Arantes (2000).

${ }^{6} 0$ termo, do qual se origina o neologismo gentrificação, deriva de gentry, que significa baixa nobreza em inglês. Foi usado pela primeira vez por Ruth Glass nos anos de 1960 ao examinar o contexto londrino, referindo-se à penetração de bairros populares por classes mais abastadas (Glass, 1964). No artigo "Paisagens urbanas pós-modernas: mapeando cultura e poder" de 1991, Sharon Zukin denomina esse processo de "enobrecimento" (Zukin, 1996). resolver o problema da moradia popular em Santos vêm se mostrando ineficientes na medida em que são contraditórias e descoladas do real, como será apresentado a seguir. A política habitacional aparece como um desdobramento da lógica privatista contida na política urbana e acaba por inviabilizar a fixação de grupos com rendimentos baixos ou até intermediários em Santos, embora estes continuem recorrendo à cidade como polo empregatício.

A escassez de terrenos e o alto valor daqueles à beira-mar, cujo preço acaba por reverberar para o restante da cidade como em um "jogo de bilhar"7, transformam Santos em um território quase inacessível. Isso repercute na chamada "mobilidade pendular" da população economicamente ativa, que significa o movimento de trabalhadores que exercem regularmente suas atividades em um município diferente daquele em que residem. De acordo com a pesquisa do Núcleo de Estudos de População - NEPO da Universidade Estadual de Campinas - UNICAMP (NEPO \& UNICAMP, 2012), esse movimento vem se intensificando na Região Metropolitana da Baixada Santista (RMBS), passando de aproximadamente 80 mil pessoas em 1980 para mais de 95 mil no ano $2000^{8}$. Segundo Jakob et al. (2006) a migração populacional das classes de baixa renda de Santos para os municípios vizinhos ${ }^{9}$ resultou na expansão territorial de áreas destinadas às classes altas na cidade, acentuando um processo de homogeneização social em Santos. 0 baixo preço

\footnotetext{
${ }^{7}$ Quando o mercado imobiliário avança em direção às áreas e moradias ocupadas pela população de baixa renda, tem-se um fenômeno denominado por Meyer (2008, p. 22) de "jogo de bilhar", ou seja, "os estratos médios, deslocados dos bairros mais nobres, parecem se mover, deslocando por sua vez, para a extrema periferia os domicílios da base social".

${ }^{8}$ Os principais destinos são Cubatão e, em especial, Santos, que respondia por $54 \%$ desse movimento em 1980 e passou para 64\% em 2000. Com relação aos municípios de origem, o estudo do NEPO \& UNICAMP (2012) aponta São Vicente como a principal cidade proveniente: em 1980, mais de 36 mil pessoas deixavam a cidade para trabalhar; em 2000, eram mais de 45 mil.

${ }^{9}$ Enquanto foi constatada uma queda expressiva na taxa anual de crescimento da Baixada Santista, que, no período de $1970-1980$, foi de 3,9\%, reduzindo para 2,2\% entre 1980-1991 e para 2,1\% entre 1991-2000, houve um crescimento significativo em municípios periféricos ao núcleo principal da região (Santos e São Vicente); em Bertioga, por exemplo, a taxa de crescimento foi 11,29\% entre 1991-2000.
} 
da terra, principalmente nos municípios de Praia Grande, Mongaguá, Itanhaém, Peruíbe e, em especial, de Bertioga, recém-emancipado, pode ter sido um dos principais fatores que mantiveram o fluxo migratório de população de baixa renda para essas cidades, apresentando saldos migratórios superiores aos da Baixada Santista, que sofreu uma desaceleração no ritmo de crescimento populacional no início da década de 1980, relacionada à recessão econômica do país.

Nesse contexto, entende-se que a dinâmica habitacional da Baixada Santista foi profundamente influenciada pela saturação do tecido urbano de Santos pelos investimentos imobiliários e, já nas décadas de 1960 e 1970, apresentava as maiores taxas de densidade demográfica e de urbanização do litoral. Contudo, a centralização espacial do emprego em Santos e o aumento gradativo da concentração de renda na cidade, por consequência direta do valor da terra, mantêm, por um lado, a cidade como núcleo e polo econômico da região, mas, por outro, inviabilizam a fixação de moradia por alguns grupos que nela trabalham, notadamente no setor de serviços. Segundo o Plano Metropolitano de Desenvolvimento Integrado
(PMDI) (Emplasa, 2002), Santos responde por 50\% dos postos de trabalho da região, o que significa uma intensa concentração de empregos no município, destacando-se o setor terciário com as atividades portuárias e de estância balneária. Contudo, apesar desse aumento no número de empregos no município, é importante ressaltar o crescimento da desigualdade social atestado pelo salto quantitativo tanto da sua renda per capita quanto do número de famílias sem renda em Santos, no período de 1980 a 2000 (Tabela 1), remontando ao processo de criação destrutiva do projeto neoliberal no plano local que, segundo Harvey $(2008,2007)$, promove um desenvolvimento desigual com aumento da concentração de riqueza e pobreza.

Embora essa dinâmica habitacional se dê em escala regional, demonstra-se aqui que Santos é o foco irradiador do problema da moradia na região, já que as políticas urbanas adotadas pela cidade tiveram - e continuam a ter - importantes reflexos na estruturação dos demais municípios da RMBS. É importante ressaltar, contudo, que Santos também sofre os impactos da segregação dessa parcela da população trabalhadora para outros municípios,

Tabela 1 - Renda per capita familiar, em salários mínimos, de 2002

\begin{tabular}{|c|c|c|c|c|c|c|c|c|c|c|c|c|}
\hline \multirow[b]{4}{*}{$\begin{array}{l}\text { Município/ } \\
\text { RMBS }\end{array}$} & \multicolumn{11}{|c|}{ RENDA PER CAPITA FAMILIAR (em salários mínimos de 2002) } & \\
\hline & \multicolumn{3}{|c|}{ Número de famílias } & \multicolumn{9}{|c|}{$\begin{array}{c}\text { \% de famílias segundo a renda per capita familiar } \\
\text { (salários mínimos) }\end{array}$} \\
\hline & \multirow[b]{2}{*}{1980} & \multirow[b]{2}{*}{1991} & \multirow[b]{2}{*}{2000} & \multicolumn{3}{|c|}{1980} & \multicolumn{3}{|c|}{1991} & \multicolumn{3}{|c|}{2000} \\
\hline & & & & 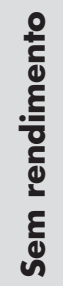 & $\begin{array}{l}\frac{\sum}{4} \\
\frac{10}{4} \\
\frac{0}{4}\end{array}$ & $\begin{array}{l}\sum \\
\tilde{y} \\
0 \\
0 \\
0 \\
0 \\
\frac{n}{0} \\
\frac{0}{2}\end{array}$ & 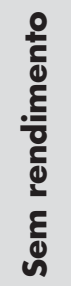 & $\begin{array}{l}\sum_{4} \\
\vdots \\
\vdots \\
\frac{0}{4}\end{array}$ & $\begin{array}{l}\sum \\
\Sigma \\
0 \\
\frac{0}{0} \\
\frac{n}{0} \\
\frac{0}{2}\end{array}$ & 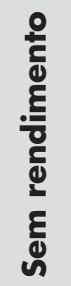 & 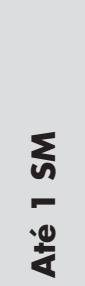 & $\begin{array}{l}\Sigma \\
n \\
0 \\
0 \\
0 \\
0 \\
\frac{0}{0} \\
\Sigma\end{array}$ \\
\hline Bertioga & - & . & 9.188 & - & - & - & - & - & - & 5,2 & 35.7 & 1,9 \\
\hline Cubatão & 22.231 & 24.790 & 32.321 & 0,8 & 30,3 & 0,7 & 3,3 & 48,5 & 0,5 & 7,9 & 41,1 & 1,0 \\
\hline Guarujá & 37.665 & 56.289 & 79.051 & 1,3 & 41,9 & 0,9 & 3,0 & 52,6 & 0,8 & 6,4 & 39,9 & 2,0 \\
\hline Itanhaém & 7.052 & 13.060 & 22.080 & 1,7 & 50,0 & 1,1 & 2,0 & 54,2 & 1,4 & 7,4 & 43,5 & 1,7 \\
\hline Mongaguá & 2.494 & 5.829 & 11.595 & 0,9 & 47,1 & 1,1 & 6,0 & 52,6 & 1,0 & 14,1 & 38,9 & 1,6 \\
\hline Peruibe & 4.656 & 9.137 & 15.386 & 2,5 & 49,9 & 2,7 & 0,9 & 53,6 & 1,4 & 7,8 & 44,1 & 2,2 \\
\hline Praia Grande & 18.287 & 34.793 & 59.777 & 2,7 & 35,5 & 1,7 & 3,1 & 49,2 & 1,0 & 6,9 & 35,2 & 2,2 \\
\hline Santos & 122.834 & 134.093 & 141.925 & 2,0 & 16,5 & 4,5 & 1,8 & 24,8 & 4,1 & 4,1 & 16,4 & 8,2 \\
\hline São Vicente & 50.190 & 76.472 & 91.175 & 2,2 & 31,6 & 1,9 & 4,4 & 42,4 & 1,4 & 7,6 & 35,1 & 2,0 \\
\hline Total RMBS & 265.399 & 354.463 & 462.387 & 1,9 & 27,3 & 2,8 & 2,9 & 39,4 & 5,6 & 6,4 & 31,4 & 3,9 \\
\hline
\end{tabular}

Fonte: NEPO \& UNICAMP (2012), elaborado com base nos censos demográficos de 1980, 1991 e 2000 (IBGE). 
considerando os movimentos pendulares que se instalaram com a dinâmica demográfica regional.

A dinâmica da segregação espacial em Santos foi sendo acentuada ao longo do século XX com o desenvolvimentismo e a industrialização da região. A criação do polo industrial petroquímico e siderúrgico de Cubatão repercutiu em uma intensa migração em busca de trabalho na construção dessas obras de grande porte. 0 contingente populacional não aproveitado pelo polo industrial foi absorvido pela construção civil em Santos nas obras do túnel ligando a zona leste ao centro, na complementação do sistema de canais até o bairro da Ponta da Praia, na reforma dos jardins da orla e na construção dos edifícios ao longo da avenida da praia. Contudo, a inexistência de políticas habitacionais eficientes em Santos e nos municípios lindeiros corroborou a precarização da moradia na região devido ao aumento dos assentamentos subnormais nas encostas da Serra do Mar próximo a Cubatão, nos manguezais e morros, ao longo das rodovias, na área continental de São Vicente, além do acréscimo significativo no número de cortiços no centro de Santos.

O Plano Diretor Físico de Santos de 1968, somado a um conjunto de leis ${ }^{10}$, ignorava as áreas ocupadas por assentamentos precários, como nos morros e mangues, mas elevou o potencial construtivo na região da orla, servindo diretamente ao mercado imobiliário. Essa prática teve como consequência não só um impacto negativo na balneabilidade das praias, dado o adensamento da orla, mas, principalmente, acentuou a segregação espacial na cidade e contribuiu para a proliferação de outros assentamentos nos municípios vizinhos a Santos (Carriço, 2002).

A partir da década de 1990, a cidade passou por administrações de orientação política progressista (Telma de Souza, PT, 1989-1992; David Capistrano, PT, 1993-1996) e o governo local passou a se envolver mais diretamente na questão habitacional de interesse social $^{11}$. A municipalidade implementou então uma política habitacional, destacando-se a elaboração do

\footnotetext{
${ }^{10}$ Código de Edificações, Lei $n^{\circ}$ 3.530; Código de Posturas, Lei $n^{\circ}$ 3.531; Normas Ordenadoras e Disciplinadoras da Urbanização e da Preservação da Paisagem Natural dos Morros, Lei nº 3.533 (Santos, 1968a, b, c).

${ }^{11}$ Soma-se a isso o desmonte do Sistema Financeiro de Habitação (SFH) na década de 1990, que embasou a política habitacional durante o regime militar.
}

Sistema Municipal de Habitação ${ }^{12}$, a criação da Zonas Especiais de Interesse Social (ZEIS) e o Programa de Locação Social ${ }^{13}$.

Dentro da perspectiva de minimizar as desigualdades sociais, em 1992, as ZEIS visavam regularizar os assentamentos precários e reservar determinadas porções da cidade para população de baixa renda. Entre 1993 e 1996, em função da orientação do orçamento municipal para a priorização da política habitacional, houve uma quantidade significativa de projetos habitacionais voltados para o setor, possibilitando o enfrentamento da segregação espacial na cidade (Figura 2). A política de habitação desse período procurou articular outras esferas de governo por meio de parcerias entre o governo federal, a Companhia de Desenvolvimento Habitacional e Urbano (CDHU), a Companhia de Habitação da Baixada Santista (COHAB-SANTISTA) e o Banco Interamericano de Desenvolvimento (BID) ${ }^{14}$.

A política urbana que se delineava na década de 1990, buscando inverter prioridades na alocação de recursos públicos a fim de minimizar as desigualdades sociais e almejando maior participação popular no processo decisório de políticas públicas, acabou gerando inúmeros impasses entre a municipalidade e o setor imobiliário. Assim, sob nova administração de orientação conservadora, essa agenda foi rapidamente substituída por uma política urbana claramente direcionada para atender aos interesses do mercado imobiliário, com a justificativa de alavancar o desenvolvimento urbano e o "progresso" de Santos. E sob a égide do planejamento estratégico, o Plano Diretor de 1998 determinou o fomento ao turismo, ao porto e ao terceiro setor (serviços) como elementos prioritários para o fortalecimento da cidade e o desenvolvimento municipal. As incipientes políticas

\footnotetext{
${ }^{12}$ Embasado em três principais elementos: o Conselho Municipal de Habitação, o Fundo de Incentivo à Construção de Habitação Popular e uma nova legislação direcionada para questão habitacional de baixa renda.

${ }^{13}$ Este programa atendeu, até 1996, a 6.228 famílias em ZEIS do Tipo 1 (áreas de favela) e 3.027 famílias em ZEIS do tipo 2 (glebas sem urbanização), em obras de urbanização de favelas, construção de novos núcleos habitacionais e projetos de regularização fundiária (Carriço, 2006).

${ }^{14} \mathrm{O}$ projeto de urbanização da favela do Dique da Vila Gilda, na zona noroeste de Santos, foi realizado com recursos do Programa Habitar Brasil-BID em parceria com a COHAB e foi o primeiro grande projeto habitacional do período.
} 


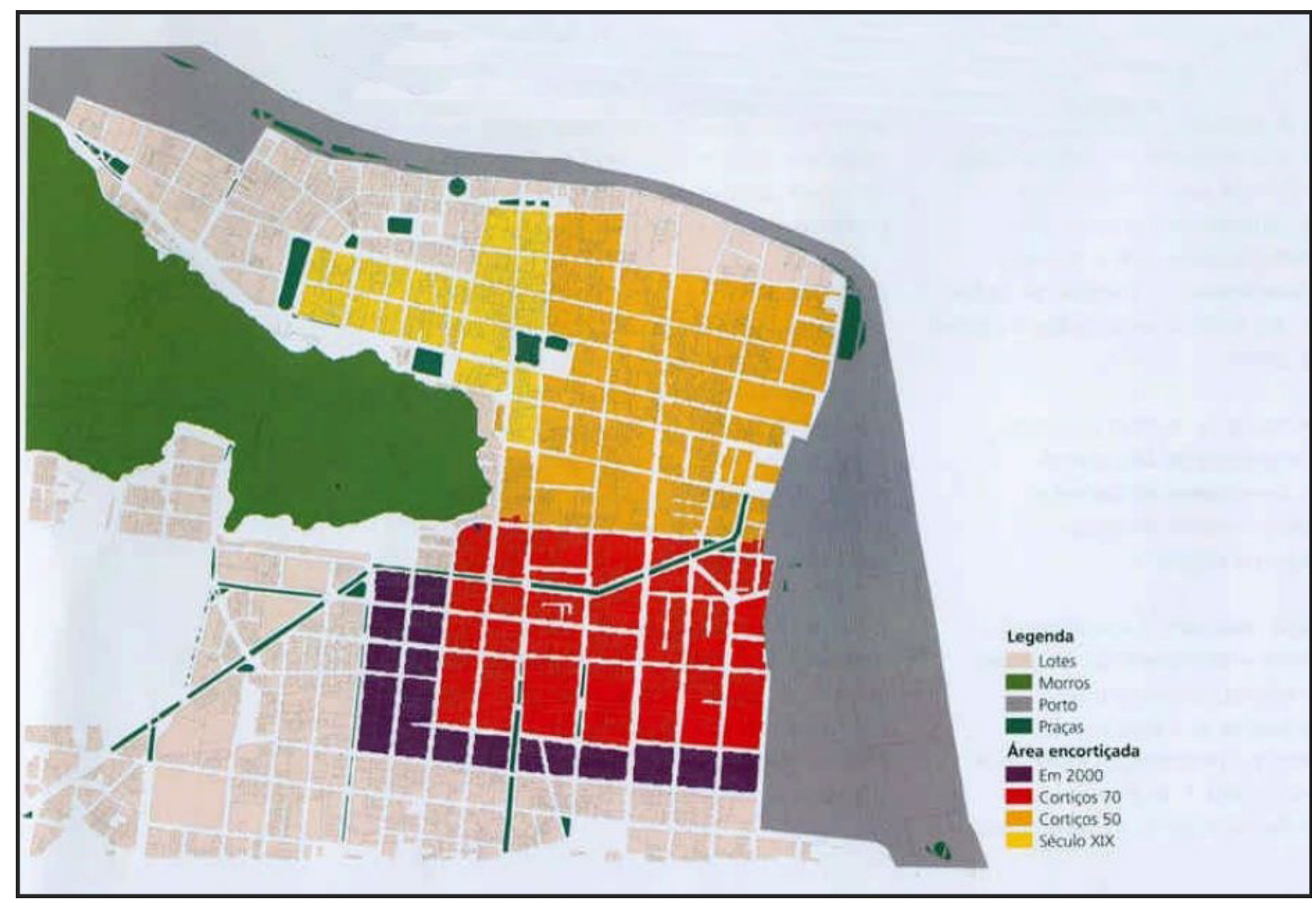

Figura 2 - Evolução da ocupação de domicílios encortiçados no município de Santos do século XIX ao ano de 2000 Fonte: CDHU (2002).

voltadas para moradia popular acabaram não sendo prioridade da gestão municipal, resultando no fracasso do enfrentamento dessa questão em Santos.

\section{fracasso do programa estadual "PAC Cortiço" em Santos}

O Pró-Lar Atuação em Cortiços (PAC Cortiços) surgiu em meados da década de 1980 na CDHU, a partir de discussões que visavam solucionar o problema das moradias subnormais, majoritariamente, nas regiões centrais das cidades ${ }^{15}$. 0 programa foi oficializado em

\footnotetext{
${ }^{15}$ 0 Pró-Lar integra os programas habitacionais da Secretaria de Habitação do Estado de São Paulo e da CDHU para garantir moradia digna e melhorar as condições de vida à população de baixa renda no Estado. Esse programa conta com diversas frentes de atuação para atender às necessidades habitacionais específicas dos municípios: Pró-Lar Atuação em Cortiços; Pró-Lar Desfavelamento; Pró-Lar Atuação em Favelas e Áreas de Risco; Pró-Lar Crédito Habitacional;
}

junho de 1998, pelo então governador do Estado de São Paulo, Mário Covas, contando com financiamento de US\$70 milhões do BID e do Governo do Estado de São Paulo para atender, em uma primeira fase, a 5 mil famílias em quatro anos. Segundo relatório da CDHU (2002), a ideia era estimular a oferta de soluções habitacionais em áreas encortiçadas que sofreram transformação de seu uso original e desinvestimento, resultando em regiões degradadas, porém com infraestrutura instalada ociosa. 0 programa seria, portanto, indutor de um processo mais amplo de revitalização urbana.

As áreas que mais interessavam ao programa eram aquelas com concentração de habitação coletiva

Pró-Lar Crédito Habitacional Carta de Crédito; Pró-Lar Lotes Próprios com Prefeituras; Pró-Lar Microcrédito Habitacional; Pró-Lar Moradias Indígenas; Pró-Lar Mutirão Associativo; Pró-Lar Núcleo Habitacional por Empreitada; Pró-Lar Autoconstrução; Pró-Lar Autoconstrução Demanda Geral; Pró-Lar Autoconstrução Loteamento Autoconstrução; Pró-Lar Rural; Pró-Lar Trabalhador Rural; Pró-Lar Regularização. 
precária de aluguel, nas quais houvesse interesse em promover programas e projetos habitacionais destinados, prioritariamente, à população de baixa renda que reside na área. Sendo assim, a ZEIS 3 era o principal alvo do PAC Cortiços, definindo o setor básico de intervenção do programa.

É importante destacar que, nesse período ${ }^{16}$, a ZEIS 3 em Santos abrangia a região da Vila Nova e Paquetá, e a população beneficiada era atendida conforme cadastro existente no órgão de planejamento ou de habitação da Prefeitura ${ }^{17}$. Entretanto, dentre as ZEIS criadas na década de 1990 em Santos, a única que não conseguiu ser efetivamente implantada foi a ZEIS 3, de intervenção na área central da cidade. Redefinida, tornou-se programa de locação social, regido por outros critérios, e "enquanto programa de locação social, os resultados quantitativos alcançados foram baixos e, ao final do governo, dois empreendimentos haviam sido concluídos" (Carvalho, 1999, p. 155).

Segundo relatório da CDHU (2003), o PAC Cortiços começou a atuar em Santos somente a partir do ano 2000, ainda visando ao planejamento da intervenção,

\footnotetext{
${ }^{16}$ É importante destacar que, desde sua aprovação, em 1992, a lei de ZEIS passou por diversas alterações no município (Santos, 1992). A última delas foi a Lei Complementar $\mathrm{n}^{\circ}$ 775 (Santos, 2012), promulgada em 23 de julho de 2012, um ano após a aprovação da revisão do Plano Diretor de Desenvolvimento e Expansão Urbana do Município e das Leis de Ordenamento do Uso e Ocupação do Solo das Áreas Insular e Continental. As principais modificações na lei de ZEIS que merecem destaque pelo avanço que trazem foram: I) a redução da renda máxima familiar para os beneficiários de novas moradias de 12 para 10 salários mínimos, priorizando famílias com renda familiar mensal de até seis salários mínimos, em condições de habitabilidade precária, que não possuam outro imóvel, com área privativa máxima em conformidade com o disposto na presente lei complementar; II) nos empreendimentos em ZEIS 2, pelo menos $50 \%$ por cento das unidades habitacionais produzidas deverão ser destinadas às famílias com renda familiar de até três salários mínimos; III) novas áreas da cidade foram designadas para construção de moradias populares, como a área da União no bairro do Jabaquara, que vinha sendo ocupada pela empresa privada do ramo de transporte de cargas (TRANSBRASA) e que passa agora a ser a maior área da cidade para fins de habitação popular.

${ }^{17}$ Podendo ocorrer os seguintes casos: a) melhoria de condições de habitabilidade em cortiços existentes; b) remanejamento de moradores para novas unidades habitacionais na mesma ZEIS-3; c) uso comercial e de serviços compatíveis com o uso residencial.
}

ou seja, a área delimitada como ZEIS-3 passou sem ações efetivas por, pelo menos, 10 anos. Na primeira fase, o levantamento dos imóveis encortiçados da área central foi feito por uma empresa de consultoria contratada pelo programa; já na segunda fase, em outubro de 2001, a Fundação SEADE foi contratada para elaboração de instrumental e coleta de dados, contendo levantamento socioeconômico sobre os domicílios, inserção das famílias encortiçadas no bairro e sua participação associativa. Segundo o programa, por meio do conhecimento aprofundado das necessidades dessas famílias, seria possível oferecer diversas alternativas de atendimento, de modo a manter essa população na região. A pesquisa limitou-se à população residente em 40 imóveis, selecionados previamente pelo CDHU segundo critérios definidos para implantação do programa. Contatou-se a situação precária dessas moradias, em sua maioria compostas por um único cômodo ( $75 \%$ dos domicílios), com uso coletivo de banheiro e tanque de lavar roupas. A maior parte dos 622 residentes (253 famílias) encontrados era de jovens e em situação econômica bastante vulnerável, com renda familiar de até três salários mínimos (em valores da época) e de origem local, ou seja, mais de $80 \%$ dos chefes de família encortiçados ficavam no município de Santos, dos quais $45,7 \%$ no mesmo bairro em que moravam na época da pesquisa. Vale salientar ainda que a maior parcela dos chefes de família $(43,5 \%)$ já vivia em Santos há mais de 20 anos e que, em cada três chefes, mais de um (38\%) já morava na cidade há, pelo menos, 10 anos.

Segundo relatório do CDHU (2003), o Pró-Lar Atuação em Cortiços já havia viabilizado um total de 740 unidades habitacionais em São Paulo e, em 2010, estava em curso a etapa do programa que contava com a participação da Secretaria de Habitação/CDHU, em parceria com o BID, como agente promotor e financeiro, além das prefeituras municipais e associações de moradores. A expectativa era a de que essa etapa beneficiasse diretamente as famílias moradoras de cortiços localizados em áreas pré-identificadas dos municípios de São Paulo, principalmente na região central da capital e de Santos.

A parceria com o BID tinha duração prevista até o final de 2010, mas em Santos foram entregues apenas dois conjuntos habitacionais pela $\mathrm{CDHU}$, totalizando 113 unidades habitacionais das 339 previstas até o fim de 2006 (Ambrósio \& Santos, 2012). Vale ressaltar que, em 2003, foi realizado pela Secretaria de 
Planejamento (SEPLAN) um censo dos moradores de cortiços dos bairros Vila Nova, Paquetá e parte da Vila Matias. A pesquisa encontrou 14.500 moradores encortiçados na cidade, e a amostra feita correspondia a 1.238 moradores integrantes de 412 famílias pesquisadas. Esse levantamento também constatou que a população era predominantemente jovem, que 86\% dessas famílias habitavam apenas um cômodo e que, embora $93 \%$ dos chefes de família estivessem economicamente ativos naquele período, apenas $47 \%$ tinham atividade profissional formal com comprovação de renda. Quanto à origem dessa população, o censo revelou que grande parte dos moradores dos cortiços já vivia no município há mais de 15 anos (46\%), dos quais $26 \%$ do total estavam no mesmo bairro há mais de 15 anos (SEPLAN, 2003). Esses dados demonstram a ausência de políticas públicas habitacionais eficientes dirigidas a essa população de baixa renda, que já estava, em 2003, há mais de 15 anos vivendo na cidade em situação precária.

Ademais, a obra dos dois conjuntos entregues pela CDHU teve seu prazo ampliado, pois foi paralisada por duas vezes devido a problemas financeiros das empreiteiras contratadas para execução do projeto. Assim, considerando-se o número de pessoas encortiçadas e em alto grau de vulnerabilidade social na área central de Santos, é notável a ineficiência da aplicação desse programa estadual no município. Ainda que a intensificação de investimentos estatais ou privados na região possa desencadear processos como o de gentrificação, com a expulsão dessa população e a substituição paulatina do comércio e serviços voltados a ela, fica evidente o pouco interesse da municipalidade em enfrentar realmente o problema dos cortiços no centro e, especialmente, em implementar políticas de fixação dessa população em uma região que voltou a ser estratégica para a manutenção da reprodutibilidade do capital na cidade.

\section{O programa municipal Alegra Centro Habitação}

O Programa de Reabilitação do Uso Residencial na Região Central Histórica de Santos, denominado Alegra Centro Habitação, foi criado pela Lei Complementar no 688, de 29 de julho de 2010, (Santos, 2010a) e integra o Plano Municipal de Habitação de Santos
(PMH) (SEPLAN, 2009) ${ }^{18}$. A lei dispõe sobre as condições de habitabilidade dos imóveis, fixando normas, padrões e incentivos fiscais específicos, com o objetivo de promover melhoria de qualidade de vida da comunidade pela requalificação das condições de moradia dos imóveis precários na região central. Propõe também fomentar o fortalecimento do comércio e a prestação de serviços na área, além da ampliação e da melhoria da rede de serviços públicos ${ }^{19}$.

0 programa estabeleceu como estratégias a concessão de incentivos fiscais para que investidores privados e proprietários promovessem a reabilitação dos imóveis com uso residencial pluri-habitacional precário ou a implantação de novas construções de uso residencial uni ou pluri-habitacional na área de abrangência. A lei também estabeleceu incentivos, obrigações e sanções aos envolvidos no processo de reabilitação a fim de construir um processo participativo. Além disso, para garantir a manutenção da população residente no local, o programa determinou que os imóveis de uso residencial pluri-habitacional precário, após serem reabilitados, deveriam ser habitados prioritariamente pelos moradores dos respectivos imóveis e que seu uso residencial deveria ser mantido por, no mínimo, cinco anos contados a partir da data da expedição da Carta de Habitação ${ }^{20}$.

O Alegra Centro Habitação pode ser considerado um desdobramento do Programa de Revitalização e Desenvolvimento da Região Central Histórica de Santos, o Alegra Centro, uma vez que este visa à retomada do desenvolvimento socioeconômico do Centro por meio do fomento à preservação do patrimônio histórico e

${ }^{18} \mathrm{O}$ plano é uma síntese do planejamento habitacional no âmbito local, tratando da questão prioritária de habitação de interesse social.

${ }^{19}$ Ver artigo primeiro da Lei Complementar no 688/ 2010 (Santos, 2010a).

${ }^{20}$ Ambrósio \& Santos (2012 p. 240) apresentam alguns pontos frágeis da lei que podem comprometer a manutenção da população residente no local: "1) questiona-se, juridicamente a capacidade da prefeitura, quanto à obrigatoriedade de congelamento dos aluguéis, no momento da intervenção da edificação e sua locação para as famílias que residirem, no local, no ato de sua inclusão no projeto; 2) a lei obriga o aluguel para os atuais moradores por apenas cinco anos, sendo que, após esse período, o proprietário pode alugar os imóveis requalificados para terceiros, não necessariamente moradores de cortiços e, assim, as famílias podem apenas ter 'adiada' sua expulsão do bairro". 
requalificação urbana, com solução habitacional na APC e sua periferia. No entanto, a área de abrangência do programa habitacional exclui a área de atuação do Alegra Centro, deixando de fora áreas em que há concentração de cortiços, como o bairro do Valongo. Para os encortiçados residentes nas áreas excluídas da contrapartida habitacional, a lei define que "as famílias moradoras de imóveis localizados no bairro do Valongo, identificados no decreto citado no caput, poderão ser direcionadas para imóveis localizados na área de abrangência do programa" ${ }^{21}$. Assim, considerando-se que as isenções fiscais concedidas pelo Alegra Centro não contemplam o uso residencial, percebe-se que a política de revitalização da área central de Santos incentiva a expulsão da população de baixa renda residente.

O texto da lei do programa habitacional utiliza termos como "viabilização da requalificação das condições de moradia", "incentivo à reabilitação dos imóveis" ou ainda "incentivo à implementação de novas unidades", mostrando o acento sobre a parceria público-privada, seja com o proprietário do imóvel ou com novos investidores. Verifica-se então que o fator determinante para o êxito da manutenção da população de baixa renda na região central é a adesão do mercado imobiliário ao programa. No entanto, diversos estudos mostram que a produção do mercado santista está voltada para produtos imobiliários de alto padrão e que não se enquadram em programas federais de financiamento (Carriço, 2002; Meyer, 2008).

O PMH indicava como meta normativa, em 2009, a articulação entre o Alegra Centro Habitação e a aplicação dos instrumentos de parcelamento, edificação e utilização compulsória e IPTU progressivo no tempo. Ele deveria também se articular a outros programas, na esfera estadual e federal, como o Plano Local Integrado de Requalificação Habitacional da Área Central e o Programa de Locação Social. Estudos indicam, no entanto, que esses instrumentos de fato não foram acionados devido, em grande parte, à não prioridade de uma política fundiária e habitacional pela administração pública em Santos (Rios, 2011).

Soma-se a isso o fato de que o programa habitacional já estava defasado em cinco anos com relação à implementação daquele voltado à revitalização do centro. Mesmo assim, foi aprovado dois anos mais

\footnotetext{
${ }^{21}$ Artigo $6^{\circ}$, III, $\S 5^{\circ}$ da Lei Complementar nํ 688/ 2010 (Santos, 2010a).
}

tarde, em 2010, ou seja, há uma lacuna de sete anos sem provisão de moradia aos encortiçados da região central.

Em 2012, segundo as responsáveis pela implantação do programa, os proprietários dos 221 imóveis identificados como de uso residencial pluri-habitacional precário foram notificados e a prefeitura deveria aguardar até o final daquele ano por interesse em participar do programa ${ }^{22}$. Não havia obrigatoriedade de adesão, mas a lei previa aplicação de multa de 50\% do valor venal do imóvel por insalubridade, se fosse o caso. Para aqueles que se interessassem, a prefeitura estabeleceu um convênio com o escritório-modelo do curso de Arquitetura e Urbanismo da Universidade Santa Cecília, que seria o responsável pelos levantamentos e propostas para adequação dos imóveis. Contudo, pouco ou nenhum material sobre o andamento do programa era disponibilizado à população, quer em site oficial ou diretamente na Secretaria Municipal de Planejamento (Figura 3).

Em 2013, a prefeitura instituiu o dia 16 de agosto como "Dia do Bairro do Centro", com a perspectiva de atrair grandes investimentos para essa região da cidade. Na ocasião, o secretário de Desenvolvimento Urbano, Nélson Gonçalves de Lima Junior, anunciou que os programas Alegra Centro e Alegra Centro Habitação passariam por uma revisão. Admitiu, inclusive, que:

Alegra Centro Habitação não aconteceu. Por isso, é necessária uma revisão absolutamente completa, para que os empresários da construção civil possam olhar o centro com mais atenção" e complementa: "é preciso que haja entusiasmo do empresariado para que se desenvolva a habitação no centro.

Assim, a implantação do programa municipal para solucionar o problema dos cortiços na região central de Santos segue vagarosamente, e seus resultados ainda são nulos ou pouco conhecidos. Como já analisado por Santos (2011), a população moradora de cortiços e habitações precárias não viu melhoria em suas condições de vida entre 2000 e 2010. A região central, segundo o Índice Paulista de Vulnerabilidade Social (IPVS) de 2000 e 2010, Fundação SEADE $(2000,2010)$, permanece com alguns dos

\footnotetext{
${ }^{22} 0$ Decreto $\mathrm{n}^{\circ} 5642$, de 29 de julho de 2010 , estabeleceu o prazo de dois anos a partir de sua publicação para a adesão dos proprietários ao programa, sem a aplicação de multa (Santos, 2010b).
} 


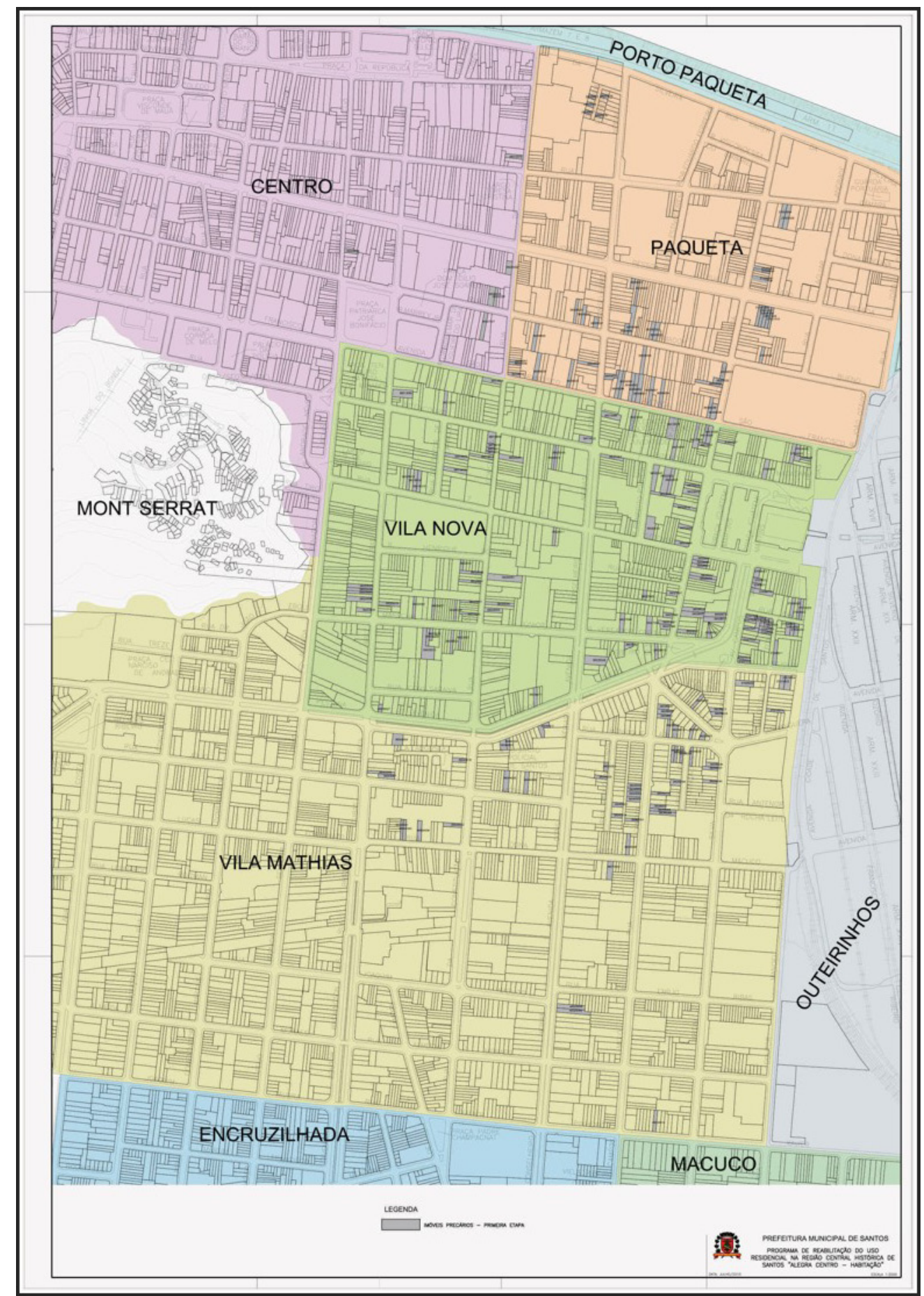

Figura 3 - Imóveis de uso pluri-habitacional precário. Único material disponível sobre o Alegra Centro Habitação no final de 2010 Fonte: SEPLAN (2010).

maiores índices de vulnerabilidade - alta (urbanos) e muito alta (aglomerados subnormais urbanos) -, demonstrando também imobilidade socioeconômica de quase totalidade dos moradores dessa área. A valorização do solo urbano promovida pelas ações de caráter elitizado do vizinho Alegra Centro acaba por transformar o programa habitacional em uma norma desvinculada da realidade, cuja aplicação é suspensa pela própria lei; é a vigência sem aplicação (Agamben, 2004).

Percebe-se que os limites estabelecidos pelo Poder Público na criação de políticas urbanas geram 
mudanças significativas que redefinem usos, funções e preços, e que influenciam diretamente na valorização ou na desvalorização dos lugares na cidade. As ações do Estado têm, mais do que nunca, papel significativo na determinação do lugar que o sujeito irá ocupar na cidade em função da relação renda/preço do $\mathrm{m}^{2}$ do solo urbano, considerando-se a formação espacial brasileira calcada, fundamentalmente, na propriedade privada.

Em Santos, as características topográficas e a reduzida dimensão do território municipal fazem com que os marcos regulatórios tenham papel fundamental para a fixação de grupos economicamente fragilizados na cidade. A ideia da raridade do solo não pode se tornar um legitimador da segregação social na Baixada Santista.

\section{Considerações finais}

O projeto de renovação urbana para o centro de Santos tem colaborado para a formação de um espaço de exceção, com consequências que extrapolam seu território. As isenções fiscais e as outras condições de exceção para atrair investidores para a região central colocaram-na, bem como o patrimônio histórico, direta e sem mediação, na esfera da política para servir aos interesses particulares. É preciso lembrar que a condição de exceção é, a princípio, uma liminar política, uma ordem provisória, para intervir na lógica de governar e ser governado. Tal condição, que deveria ser extraordinária, é usada dentro do sistema capitalista sob a metáfora da guerra - neste caso, entre cidades - para garantir a reprodutibilidade do capital. Medidas excepcionais são transformadas em técnica de governo, e o espaço urbano torna-se a nova fronteira de acumulação do capital (Agamben, 2004; Harvey, 2013).

Desde 2014, o marco regulatório de Santos está em revisão e, dessa vez, foram apresentadas propostas significativas para o ordenamento do solo com soluções habitacionais variadas. Diferente do plano anterior, há uma ampliação da demarcação de ZEIS 3 prevista, principalmente, para área central da cidade, onde há inúmeros cortiços. Segundo pesquisa recente do Instituto Polis realizada em 2012/2013 (A Tribuna, 2015), há em Santos, somente na área insular, 78.321 moradores em 34 assentamentos precários não só nos morros, mas nas palafitas da zona noroeste e nos cortiços do centro (A Tribuna, 2015). Diversos estudos brasileiros já demonstraram a importância da ZEIS 3 como instrumento para manutenção da população de baixa renda em áreas de renovação urbana, como em Operações Urbanas Consorciadas.

Contudo, os projetos Alegra Centro e Alegra Centro Habitação ainda encontram-se suspensos. o que parece claro é que a divisão maniqueísta entre recuperação patrimonial e moradia em projetos de renovação urbana tem conduzido à segregação espacial e à aceleração da desigualdade. A moradia deve ser entendida como parte do processo histórico da área central, e as propostas deveriam contemplar mecanismos para integração de políticas setoriais de diferentes níveis de governo, com a indicação de modelos de financiamento do projeto. Esse dado é fundamental para a viabilização das propostas de renovação urbana, na medida em que envolvem grandes investimentos de recursos. Também é basilar que o marco regulatório avance a fim de garantir estabilidade e continuidade na implantação do projeto, definindo sua execução por etapas ou fases de implantação. Do mesmo modo, para efetivar a democratização do acesso a terra urbana, deve conter regras claras para a valoração inicial e final do solo urbano e dos imóveis, especialmente se as unidades forem destinadas a população de baixa renda.

Para além do enfrentamento do déficit e da precariedade habitacional, está em jogo a produção de um território mais democrático e inclusivo, tanto na escala intraurbana quanto metropolitana. Apesar da integração territorial da RMBS, a questão da habitação de interesse social não aparece como prioridade na agenda do órgão regulador metropolitano ${ }^{23}$. Entretanto, a consequência da ineficácia de políticas voltadas para provisão de moradia popular em Santos tem influenciado diretamente a dinâmica das cidades vizinhas, especialmente do ponto de vista da mobilidade.

Na operação dessa riqueza cultural preexistente, que é a estrutura patrimonial do centro, encontra-se uma oportunidade estratégica de gerar uma relação

\footnotetext{
${ }^{23}$ Agência Metropolitana da Baixada Santista (AGEM), vinculada à Secretaria de Desenvolvimento Metropolitano, é uma autarquia do governo criada por meio da Lei Complementar Estadual no 853/1998, com sede e foro em município da RMBS. Tem por finalidade integrar a organização, o planejamento e a execução das funções públicas de interesse comum na RMBS (São Paulo, 1998).
} 
de empatia entre diversas classes sociais em uma cidade de recursos territoriais limitados, com carência de espaços que ofereçam infraestrutura, serviços essenciais e trabalho já consolidados. Da fricção e do compartilhamento das diversas formas de uso dessa estrutura patrimonial, incluindo a moradia, será possível perceber a importância da região central como suporte de significados e a possibilidade de minimizar a desigualdade dos lugares, que podem atender a camadas de interesses diferentes, mas não excludentes.

\section{Referências}

A Tribuna. (2015, 11 de março). Programa impede ocupações irregulares. A Tribuna, caderno Cidades, A-7. Recuperado em 12 de março de 2015, de http://sites.unisanta.br/ hemeroteca/arquivos/a1643.pdf

Agamben, G. (2004). Estado de Exceção. São Paulo: Boitempo. Ambrósio, R. P., \& Santos, A. R. (2012). Entre o discurso e a prática: uma reconstituição do processo de revitalização do Centro e Santos após duas décadas. In D. A. Vazquez (Org.), A questão urbana na Baixada Santista: políticas, vulnerabilidades e desafios para o desenvolvimento ( $\mathrm{p}$. 223-245). Santos: Leopoldianum.

Arantes, O. (2000). Uma estratégia fatal: a cultura nas novas gestões urbanas. In O. Arantes, E. Maricato, \& C. Vainer, $A$ cidade do pensamento único (p. 11-75). Petrópolis: Vozes.

Bernardini, S. (2006). Os planos da cidade: as políticas de intervenção urbana em Santos: de Estevan Fuertes a Saturnino de Brito (1892-1910). São Carlos: RIMA.

Campante, R. G. (2003). Patrimonialismo em Faoro e Weber e a sociologia brasileira. Dados: Revista de Ciências Sociais, 46(1), 153-193.

Carriço, J. M. (2002). Legislação urbanística e segregação espacial nos municípios centrais da região metropolitana da Baixada Santista (Dissertação de mestrado). Faculdade de Arquitetura e Urbanismo da USP, Universidade de São Paulo, São Paulo.

Carriço, J. M. (2006). Baixada Santista: transformações produtivas e sócio-espaciais na crise do capitalismo após a década de 1980 (Tese de doutorado), Faculdade de Arquitetura e Urbanismo da USP, São Paulo.
Carvalho, S. N. (1999). Planejamento urbano e democracia: a experiência de Santos (Tese de doutorado). Instituto de Filosofia e Ciências Humanas, Universidade Estadual de Campinas, Campinas.

Companhia de Desenvolvimento Habitacional e Urbano do Estado de São Paulo - CDHU. (2002). PAC: Programa de Atuação em Cortiços: pesquisa sócio-econômica. São Paulo: CDHU.

Companhia de Desenvolvimento Habitacional e Urbano do Estado de São Paulo - CDHU. (2003). PRÓ-LAR: Atuação em Cortiços: manual do programa. São Paulo: DPP. Recuperado em 19 de fevereiro de 2016, de http://portalshcdhu.cdhu. sp.gov.br/http/informacoes/manuais/prolar/Atuação\%20 em\%20Cortiço\%20-\%20Manual\%20do\%20Programa\%20 $+\% 20$ anexos.pdf

Emplasa. (2002). Plano Metropolitano de Desenvolvimento Integrado da Região Metropolitana da Baixada Santista PMDI RMBS. São Paulo: Emplasa.

Faoro, R. (1958). Os donos do poder. Formação do patronato político brasileiro. São Paulo: Globo.

Fundação Sistema Estadual de Análise de Dados - Fundação SEADE. (2000). IPVS: Índice Paulista de Vulnerabilidade Social. São Paulo: SEADE. Recuperado em 19 de fevereiro de 2016, de http://www.seade.gov.br/analises-e-estudos/

Fundação Sistema Estadual de Análise de Dados Fundação SEADE. (2010). IPVS: Índice Paulista de Vulnerabilidade Social. São Paulo: SEADE. Recuperado em 19 de fevereiro de 2016, de http://www.seade.gov.br/ indice-paulista-de-vulnerabilidade-social-ipvs-versao-2010/

Glass, R. (1964). London: aspects of change. Londres: MacGibbon \& Kee.

Harvey, D. (2007). Neoliberalism as creative destruction. Annals of the American Academy of Political and Social Science, 610(1), 21-44.

Harvey, D. (2008). O neoliberalismo: história e implicações. São Paulo: Loyola.

Harvey, D. (2013). Limites do Capital. São Paulo: Boitempo. Jakob, A. A. E., Cunha, J. M.P., \& Young, A. F. (2006) Dinâmica Demográfica Intrametropolitana na Região Metropolitana da Baixada Santista no período pós-1970. In J. M. P. Cunha (Org.), Novas Metrópoles Paulistas: população, vulnerabilidade e segregação (Vol. 1, p. 399-434). Campinas: Nepo/Unicamp. 
Maziviero, M. C. (2008). Memória e Identidade Urbana em Santos: usos e preservação de tipologias arquitetônicas da Avenida Conselheiro Nébias (Dissertação de mestrado). Faculdade de Arquitetura e Urbanismo da USP, Universidade de São Paulo, São Paulo.

Meyer, J. F. P. (2008). Demanda residencial: adequação da análise de mercado imobiliário, o caso de São Paulo (Tese de doutorado). Faculdade de Arquitetura e Urbanismo da USP, Universidade de São Paulo, São Paulo.

Novais, P. (2010). Uma estratégia chamada "planejamento estratégico": deslocamentos espaciais e a atribuição de sentidos na teoria do planejamento urbano. Rio de Janeiro: 7 letras.

Núcleo de Estudos da População - NEPO, Universidade Estadual de Campinas - UNICAMP. (2012). Atlas da Região Metropolitana da Baixada Santista. Campinas: Nepo/ Unicamp. Recuperado em 01 julho de 2012, de http:// www.nepo.unicamp.br/vulnerabilidade/atlas/atlas_santos/ Atlas_Final/index.htm

Nunes, L. A. P. (2001). Saber técnico e legislação: a formação do urbanismo em Santos - 1894 a 1951. (Dissertação de mestrado). Faculdade de Arquitetura e Urbanismo da USP, Universidade de São Paulo, São Paulo.

Rios, L. G. (2011). 0 processo de revisão do Plano Diretor de Santos à luz das diretrizes do Estatuto das Cidades. In D. A. Vazquez (Org.), A questão urbana na Baixada Santista: políticas, vulnerabilidades e desafios para o desenvolvimento (p. 121-145). Santos: Leopoldianum.

Santos, A. R. (2011). Habitação precária e os cortiços da área central de Santos. Cadernos Metrópole, 13(26), 549-571.

Santos, A. R. (2014). Revitalização para quem? Política urbana e gentrificação no Centro de Santos. Cadernos Metrópole, 16(32), 587-607.

Santos. Câmara Municipal. (1968a, 16 de abril). Lei $n^{\circ}$ 3.530: código de edificações do Município de Santos. Santos: Câmara Municipal de Santos. Recuperado em 19 de fevereiro de 2016, de http://legislacao.camarasantos. sp.gov.br/Normas/Exibir/8572

Santos. Câmara Municipal. (1968b, 16 de abril). Lei $n^{\circ}$ 3.531: código de posturas do Município de Santos. Santos: Câmara Municipal de Santos. Recuperado em 19 de fevereiro de 2016, de http://legislacao.camarasantos.sp.gov.br/ Normas/Exibir/8572

Santos Câmara Municipal. (1968c, 16 de abril). Lei $n^{\circ}$ 3.533: normas ordenadoras e disciplinadoras da urbanização $e$ da preservação da paisagem natural dos morros. Santos: Câmara Municipal de Santos. Recuperado em 19 de fevereiro de 2016, de http://legislacao.camarasantos.sp.gov.br/ Normas/Exibir/8572

Santos. Câmara Municipal. (1968d, 16 de abril). Lei $n^{o}$ 3529: plano diretor físico do Município de Santos. Santos: Câmara Municipal de Santos. Recuperado em 19 de fevereiro de 2016, de http://legislacao.camarasantos.sp.gov.br/ Normas/Exibir/3059

Santos. Câmara Municipal. (1992, 15 de maio). Lei $n^{\underline{o}}$ 53: lei de ZEIS: dispõe sobre a criação de Zonas Especiais de Interesse Social. Santos: Câmara Municipal de Santos. Recuperado em 19 de fevereiro de 2016, de http:// legislacao.camarasantos.sp.gov.br/Normas/Exibir/5318

Santos. Prefeitura Municipal. Secretaria Municipal de Planejamento. (2003, 05 de fevereiro). Lei complementar $n^{-}$ 470: Programa Alegra Centro. Santos: Prefeitura de Santos. Recuperado em 19 de fevereiro de 2016, de http://www. santos.sp.gov.br/sites/default/files/conteudo/LC_47003_e_suas_altera $\%$ C3\%A7\%C3\%B5es_Alegra_cor.pdf

Santos. Prefeitura Municipal. (2010a, 29 de julho). Lei Complementar no 688: Programa de Reabilitação do Uso Residencial na Região Central Histórica de Santos: Alegra Centro Habitação. Santos: Prefeitura de Santos. Recuperado em 19 de fevereiro de 2016, de http://www.santos.sp.gov. $\mathrm{br} /$ sites/default/files/conteudo/L.C.\%20688,\%20de\%20 29\%20de\%20julho\%20de\%202010_0.pdf

Santos. Prefeitura Municipal. (2010b, 29 de julho). Decreto $n^{-}$ 5.642: regulamenta o disposto no artigo $6^{\circ}$ da Lei Complementar $n^{\circ} 688$, de 29 de Julho de 2010. Santos: Prefeitura de Santos. Recuperado em 19 de fevereiro de 2016, de https://egov. santos.sp.gov.br/legis/document $/$ ?code $=3112 \&$ tid $=66$

Santos. Câmara Municipal. (2012, 23 de julho). Lei Complementar no ${ }^{\circ}$ 775: altera dispositivo da Lei Complementar $n^{\circ}$ 53, de 15 de maio de 1992. Santos: Câmara Municipal de Santos. Recuperado em 19 de fevereiro de 2016, de http://legislacao.camarasantos.sp.gov.br/Normas/ Exibir/5120\#68837

Santos. Prefeitura Municipal. (2013). Prefeitura projeta ampla reforma no 'Alegra Centro'. Santos: Portal de notícias da Prefeitura Municipal de Santos. Recuperado em 16 de agosto de 2013, de http://www.santos.sp.gov.br/noticia/80324/ prefeitura-projeta-ampla-reforma-no-alegra-centro

São Paulo. Estado (1998, 23 de dezembro). Lei Complementar Estadual no 853: dispõe sobre a criação da Agência Metropolitana da Baixada Santista - AGEM. São Paulo: Assembleia Legislativa do Estado. Recuperado em 
19 de fevereiro de 2016, de http://www.al.sp.gov.br/ norma/?id=7348

Secretaria de Planejamento da Prefeitura Municipal de Santos - SEPLAN. (2003). Censo dos moradores de cortiços dos bairros Vila Nova, Paquetá e parte da Vila Matias. Santos: SEPLAN.

Secretaria de Planejamento da Prefeitura Municipal de Santos - SEPLAN. (2009). Plano Municipal de Habitação de Santos. Santos: SEPLAN.

Secretaria de Planejamento da Prefeitura Municipal de Santos - SEPLAN. (2010). Mapa dos imóveis de uso plurihabitacional precário. Santos: SEPLAN.
Secretaria de Planejamento da Prefeitura Municipal de Santos - SEPLAN. (2015). Área de atuação do Programa Alegra Centro. Santos: SEPLAN.

Souza, C. D. C. (2012). Santos e o processo de requalificação de áreas portuária sobre a perspectiva do planejamento urbano (Tese de doutorado). Faculdade de Arquitetura e Urbanismo, Universidade de São Paulo, São Paulo.

Zukin, S. (1996). Paisagens urbanas pós-modernas: mapeando cultura e poder. In: Revista do Patrimônio Histórico e Artístico Nacional (p. 205-219). Rio de Janeiro: Instituto do Patrimônio Histórico e Artístico Nacional (Iphan), no 24.

Recebido: Jun. 01, 2015

Aprovado: Aug. 14, 2015 